Stoa

Vol. 11 , no. 21 , 2020, pp. 59-81

ISSN 2007-1868

\title{
EXPERIÊNCIA MATERIAL DOS VALORES E SUA APREENSÃO NA FENOMENOLOGIA AXIOLÓGICA DE MAX SCHELER
}

Material experience of values and your apprehension

in Max Scheler axiological phenomenology

Roberto KAHLMEYER-MERTENS

Universidade Estadual do Oeste do Paraná

kahlmeyermertens@gmail.com

RESUMO: O artigo tem o propósito de apresentar os traços mais insinuantes da assim chamada filosofia dos valores de Max Scheler. A apresentação indicará que valores possuem caráter apriorístico, podendo apenas ser tomados sentimentalmente. Também introduz os termos da crítica scheleriana à doutrina moral de Kant, que incorreria num formalismo cego à materialidade fenomenal dos valores.

PALAVRAS CHAVE: Experiência material dos valores - Axiologia fenomenológica · filosofia dos valores $\cdot$ Formalismo na ética $\cdot$ Scheler.

RESUMEN: El artículo tiene como objetivo presentar las características más insinuantes de la llamada filosofía de valores de Max Scheler. La presentación indicará qué valores tienen un carácter a priori y solo pueden tomarse sentimentalmente. También introduce los términos de la crítica de Scheler a la doctrina moral de Kant, que incurriría en un formalismo ciego a la materialidad fenomenal de los valores.

PALABRAS CLAVE: Experiencia material de valores - Axiología fenomenológica · Filosofía de los valores · Formalismo en la ética $\cdot$ Scheler.

ABSTRACT: The article aims to present the most insinuating features of Max Scheler's so-called philosophy of values. The presentation will indicate that values have a priori character and can only be taken sentimentally. It also introduces the terms of Scheler's

Recibido 18 de noviembre de 2019

Aceptado 15 de diciembre de 2019 
critique of Kant's moral doctrine, that incur a blind formalism to the phenomenal materiality of values.

KEYWORDS: Material experience of values - Phenomenological Axiology - Philosophy of Values · Formalism in Ethics $\cdot$ Scheler

\section{Introdução}

Não é preciso procurar muito na literatura de comentário à filosofia de Max Scheler (1874-1928) para encontrar tentativas de definir sua contribuição à filosofia, em contraste ao enfoque husserliano da seguinte forma: "Husserl era antes de tudo um lógico, uma mente formada na meditação matemática; Scheler preferia tanto mais o homem, e se preocupava principalmente com os problemas do espírito e dos valores" (Romero apud Souza, 1953, p.25). Para o momento, importa ressaltar que, do mesmo modo como Husserl se ocupa fenomenologicamente do objeto do conhecimento, visando nele sua idealidade, Max Scheler se volta aos objetos referidos à ética, interessado em sua determinação axiológico-essencial. É o filósofo de Munique mesmo quem admite que os importantes trabalhos de Husserl ofereceram a consciência metodológica própria da atitude fenomenológica para esse empreendimento (Scheler, 2000).

O que teria despertado o interesse de nosso filósofo pela fenomenologia a ponto de ligá-lo a ela por laços tão intensos? Scheler viu que a fenomenologia, tal como consignada nas Investigações Lógicas (1900), de Husserl, proporcionaria um renovo ao conhecimento. Esta, afinal, lograria um conhecimento verdadeiramente apodítico e livre dos riscos dos relativismos. Nosso filósofo compreendeu que, com a fenomenologia, mais do que a possibilidade de se intuir categorialmente conteúdos gnosiológicos (= do conhecimento), se viabilizaria também a possibilidade de tomar a objetividade ideal de conteúdos axiológicos (= valores) no solo imediato das vivências puras.

Ora, estão bem documentados os laços que ligam Scheler ao movimento fenomenológico e do quanto nosso filósofo se apossou dos seus princípios e posições de modo muito peculiar. Assim, se conceitos na pauta de Scheler, como os de "intencionalidade", da "vivência" e da "intuição" são identificados como pertencentes ao repertório fenomenológico, também é certo o serviço que, por determinado tempo, eles se prestaram ao pensamento scheleriano, cujos interesses axiológicos, éticos e antropológicos são alentados pelo filósofo desde o início de sua formação. 
É nesses campos, inclusive, que estão as principais contribuições de Scheler à filosofia. Conhecendo bem os termos da conversão idealista de Husserl, a ponto de sustentar sua oposição a ela, e tendo em proximidade os marcos da fenomenologia das Investigações lógicas, nosso filósofo delimita traço até então inexplorado no pensamento husserliano, qual seja, o da intencionalidade dos sentimentos. Com ela, Scheler mostrará que a fenomenologia também torna pensável uma ética, isso porque, à luz da fenomenologia, mesmo os sentimentos são atos de consciência e, por meio disso, nos distanciamos da compreensão de sentimento enquanto estados psíquicos que expressam a interioridade do sujeito. Observando o modelo intencional da fenomenologia husserliana, também o sentimento (Gefühl) corresponde intencionalmente a algo sentido (gefühlt), o que indica um objeto valorativo correlato à consciência. Uma experiência do valor enquanto traço essencial é o que chegamos a ter e, nesse caso, o valor não seria resultado de um juízo de bem ou de mal ou de qualquer mediação representativa do âmbito da razão prática, mas da apreensão imediata de seu conteúdo axiológico num terreno vivencial aberto pela referida intencionalidade sentimental.

Significa dizer que, com a fenomenologia de Scheler, passamos a contar com outra categoria de objetos da consciência, matéria de um tipo de saber não obtido pelo entendimento, mas no campo indomesticado e espontâneo do sentir (fühlen). Scheler passará a ter estofo necessário para estabelecer uma crítica às éticas tradicionais, uma vez que, desde tal posição, qualquer princípio, imperativo, critério, máxima ou norma e, ainda, qualquer juízo de valor acerca de coisas ou de circunstâncias, já seria epigonal ao valor, elemento primordial da experiência ética já manifesto no campo da vivência dos sentimentos. Tal achado fenomenológico permite a nosso filósofo elaborar refinadas análises no tocante ao papel dos sentimentos no campo de uma "axio-

logia fenomenológica" e, ainda, endereçar uma crítica ao que ele avalia como certo formalismo reinante na ética contemporânea.

\section{De uma axiologia fenomenológica}

Está claro que Scheler, em seu O formalismo na ética e uma ética material dos valores (1913), desenvolve uma teoria do valor. Ali, o filósofo indica o "valor" (Wert) como tomado no espaço fenomenal em que ele pode ser vivenciado. Isso é indício de que nossa experiência de consciência também é intencionalmente aberta a fenômenos cujos conteúdos, diversamente daqueles correlatos aos atos da consciência cognoscente, são experienciados. Assim, o conteúdo 
específico dos valores, tema primordial para a axiologia, não é um problema para a lógica pura. Na nova classe de vivências intencionais fenomenologicamente descoberta por Scheler, o que se dá são os valores e estes "[...] já o são como fenômenos de valor (Wertphänomene) [...], genuínos objetos (echte Gegenstände) [...]" (Sánchez-Migallón 2010, p. 45). Nosso filósofo compreende valores como a determinação essencial do valer ou, em suas próprias palavras, de "qualidades de valor" (Wertqualitäten) (Scheler 2000, p.35). Daí a importância de indicar que eles, longe de uma abstração formal, possuem cariz objetivo.

Buscando fazer com que seu leitor, mais do que entender, possa se aproximar dessa qualidade axiológica, o fenomenólogo descreve os valores de modo a evidenciar a experiência desses mesmos valores. Mas como Scheler operaria isso? À semelhança de Aristóteles, que parte da aisthesis à sophia, o alemão começa por considerar o que lhe é mais simples e imediato para só depois alçar ao complexo e ao avançado. Por isso, nosso fenomenólogo segue dos valores sensíveis aos espirituais, como ele próprio descreve aqui:

De início, intentamos tratar [a investigação] em termos de valores mais simples, tomados no âmbito do agradável sensível, i.e., desde onde a ligação da qualidade de valor (Wertqualität) com seu portador coisal (Träger dinglichen) é mais íntima do que se pensa. Cada fruta de bom sabor tem seu modo peculiar de bom sabor. Não procede, pois, que o mesmo bom sabor se misture nas múltiplas sensações que oferecem, p. ex.: a cereja, o damasco e o pêssego ao paladar, à vista e ao tato. $\mathrm{O}$ bom sabor é, em cada um desses casos, qualitativamente diverso dos outros; [...]. As qualidades de valor que possuem o "agradável sensível", nesses casos, são, elas mesmas, genuínas qualidades de valor (echte Qualitäten des Wertes selbst). (Scheler 2000, p.35).

Como se divisa aqui, partindo dos valores sensíveis, Scheler pretende reforçar a ideia consignada anteriormente de que valores são qualidades; do mesmo modo, distingue tais qualidades axiológicas de aquilo de que elas são qualidades. A palavra "portador", utilizada na citação acima e em outra anterior, agora é alçada ao primeiro plano, por nomear o que traria consigo tais qualidades valorosas (= valores). Assim, quando o filósofo usa o exemplo das frutas, pretende mostrar que, seja qual for seu portador (indiferente se a cereja, o damasco ou o pêssego), o valor de "agradável", de "bom de sabor", se manifesta objetivamente como qualidade.

Como ainda se vê na citação, começar pelos valores sensíveis oferece certa dificuldade ao filósofo em bem discriminar os valores de seus porta- 
dores coisais, uma vez que, no âmbito do sensível, tal vínculo é discreto. Nosso fenomenólogo, entretanto, investe na obtenção de clareza quanto a tal diferenciação desde o início, estimando que a conquista da pretendida nitidez com respeito à independência dos valores nesse momento viria a beneficiá-lo quando outros valores menos íntimos a seus portadores forem examinados. Desse modo, Scheler insistirá em exemplos que ajudam a ressaltar a independência dos valores sensíveis frente a seus portadores, como ainda se vê aqui:

Posso referir-me a um vermelho como um mero Quale extensivo, p. ex., como pura cor espectral que os dados me trazem, sem que esta necessariamente cubra uma superfície corpórea, como uma face ou um espaço. Assim também valores (como agradável, encantador, adorável, mas também amigável, singular, nobre) são acessíveis, a princípio, sem que eu os represente como propriedades de coisas ou de homens. (Scheler 2000, p. 35).

Como no exemplo da cor vermelha, o modo de ser axiológico de algo, para Scheler, independe de sua constituição coisal, i.e., não depende de seu portador. Do mesmo modo, valores também não nos remetem a qualquer projeção, representação, dedução, orçamento psicológico ou construção social que dele façamos. Ilustra-se essa dupla independência com duas passagens do texto de nosso filósofo, extratos apenas possíveis de serem formulados na medida em que sua investigação intensifica o esforço por dirigir-se cada vez mais ao fulcro do fenômeno visado. Primeiramente:

[... o valor de uma coisa já se dá como clara e evidentemente para nós, sem que nos estejam dados ainda os portadores deste valor. Assim, p. ex., um homem é desagradável e nojento, ou afável e simpático, sem que sejamos capazes de explicar por que isto acontece; assim tomamos um poema ou uma obra de arte por muito tempo como "bela", como "odiável", como "singular" ou "vulgar", sem que nem de longe conheçamos as propriedades de conteúdo (Eigenschaften des betreffenden) da imagem em questão; da mesma forma, a permanência em um lugar resulta "acolhedora" ou "incômoda", sem que os portadores desses valores nos sejam conhecidos. (Scheler 2000, p. 40).

Depois, o filósofo ainda acrescenta:

Nem a experiência de valores (Erfahrung des Wertes), nem o grau de adequação e evidência (a adequação em sentido pleno mais evidencia o "dar-se por si mesmo" do valor) se mostra dependente da experiência dos portadores daqueles valores. 
[...] Nesses casos se revela, com toda sua clareza, como os valores, em seu ser, independem de seu portador. (Scheler 2000, p. 40).

Afirmar que os valores são independentes das coisas que os portam possui uma implicação imediata - significa evidenciar o caráter apriorístico dos valores. Isso significa que, por mais que os valores sejam experimentados na manifestação de um objeto de valor que traz sua determinação valorosa, tal qualidade axiológica não se confunde, tampouco depende de condicionamentos dados por esse que a porta. Significa dizer que a fenomenologia dos valores de Scheler (em afinidade à primeira filosofia de Husserl) também opera de modo a intuir, acompanhando a dinâmica intencional própria ao fenômeno, desde a vivência de seu conteúdo objetivo, sua idealidade sendo capaz de evidenciá-la.

Destarte, diferentemente do que algumas interpretações da obra de Scheler sugerem, falar do caráter apriorístico dos valores como independente dos portadores não deve dar vez à pressuposição de que valores pudessem ser tratados sem que se levasse em conta uma experiência de consciência desses mesmos valores. O motivo de tal afirmativa é claro, pois, se as coisas se dessem de modo contrário, isso nos distanciaria daquele preceito fenomenológico de base segundo o qual a idealidade (= essência) de algo é o que se permite evidenciar a partir do fenômeno, sendo, portanto, o fenômeno o que dá a medida da investigação fenomenológica.

Assim, portanto, considerando que Scheler é um fenomenólogo ou, pelo menos, que no período em que escreve a sua Ética está comprometido com esse método, atitude e modo de filosofar, seria inaceitável sustentar que valores constituíssem essências por detrás do manifesto. Decorre que, se seguirmos estritamente o que ensina a fenomenologia, mais plausível seria acolher que (do mesmo modo como os atos de consciência já carreiam sentido, de tal modo o conteúdo objetivo de um fenômeno já é vivenciado como preenchido por sua significação) na intencionalidade própria aos valores. Já os vivenciamos como valorosos, no sentido de que sua essência valorosa transparece na experiência que fazemos dos objetos fenomenais, sem que, todavia, se confunda com eles, sem que a eles se reduza. (Ramos, 2017). Assim, da mesma maneira que um objeto fenomenal é o que significa, o valor, enquanto objeto fenomenal axiológico, é o que vale ${ }^{2}$. Isso nos leva a afirmar

2 A equivalência entre "ser" e "valer", aqui, dá-se da mesma maneira na filosofia de Hermann Lotze, para a qual do valor só se pode dizer que ele vale. 
que, quando Scheler procura evidenciar o caráter a priori dos valores, ele visa mais o modo como tal fenômeno é pura, imediata e indelevelmente vivenciado como valência do que um elemento pertencente a um presumido mundo de ideias (Derisi, 1979).

Em razão dessa valência, enquanto determinação axiológico-essencial das coisas, valores são identificados em sua vigência objetiva e, portanto, com validade análoga a dos objetos da lógica ou da matemática que Husserl tinha em vista em suas investigações; desse modo, reaproveitando o exemplo de Scheler, as coisas ou atitudes se apresentam imediatamente como agradáveis ou desagradáveis, sem que tenhamos vez de interferir no modo como seu valor, essencialmente, já se nos dá (isso nos leva a depreender que qualquer juízo, atribuição, interpretação ou revisão de valor já é operado no "mundo das coisas", a que o filósofo chamou de mundo de bens).

A distinção entre bens e valores, crucial nos capítulos mais adiantados de sua Ética, é introduzida aqui por meio de uma das passagens mais claras daquela obra de Scheler:

O bem está para a qualidade de valor, assim como a coisa (Ding) está para as qualidades sentidas em suas "propriedades". Com isto fica dito que devemos diferenciar entre os bens, i.e., as "coisas de valor" (Wertdingen) e os meros valores (bloßen Werten) que as coisas "tem", que as coisas "possuem", i.e., os "valores da coisa" (Dingwerten). Os bens não estão fundados nas coisas, de modo que algo deveria ser primeiramente coisa para poder ser "bem". Mais que isso, o bem põe uma unidade "coisal" de qualidades de valor ou de comportamentos valorosos (Wertqualitäten resp. Wertverhalten), que está fundada em determinado valor fundamental (Grundwert). (Scheler 2000, pp. 42-43).

Após esta exposição, mesmo o leitor inteirado apenas dos rudimentos do pensamento fenomenológico será capaz de identificar o quanto Scheler, com o ímpeto próprio à fenomenologia de "ir às coisas mesmas", amolda a intuição categorial husserliana aos propósitos de sua filosofia dos valores. Aqui, bem como lá, teríamos a possibilidade de uma intuição da essência (Wesenschau) dos fenômenos, no entanto aqui temos fenômenos de valor e qualquer intuição possível aqui seria Wertschau (uma intuição do valor); Scheler se referirá a essa Wertschau na maior parte das vezes por meio da palavra "experiência" (Erfahrung), não recorrendo ao termo "intuição", talvez para evitar a sombra do intelectualismo e as acusações a este respeito que, mais tarde, seriam endereçadas a Husserl. 
Max Scheler sustenta que qualquer pessoa é capaz de uma experiência dos valores, salientando que (além de não depender da coisa que a traz) a materialidade dos valores é independente de qualquer mediação intelectiva ou elaboração racional. Dessa sorte, a tomada da essência axiológica de algo agradável, útil ou bom não se dá cognitivamente (isso porque não conhecemos o que é um valor), senão que se dá sentimental ou emocionalmente (pois o valor é sentido enquanto o que vale).

Ressaltemos que, ao falarmos especificamente de materialidade do valor, é a seu próprio "conteúdo" essencial que nos referimos (Frings, 2001). Assim, em uma ética material dos valores — projeto eminentemente fenomenológico-, "O material é a estrutura eidética que condiciona a percepção cotidiana e a observação científica" (Kelly 2011, p.19). É o elemento material a priori, portanto, que fornece a Scheler evidência para indicar, na base de uma axiologia fenomenológica, os valores como determinações primordiais do ente; esse elemento material também é o que permite a Scheler se colocar na posição da qual parte sua crítica autoral a certo formalismo na ética, tarefa que o filósofo pondera ser urgente à filosofia de seu tempo.

\section{A crítica ao formalismo na ética}

Por estar aberta à experiência material dos valores, a filosofia fenomenológica de Max Scheler pode examinar o conhecimento e a conduta moral de sua época diagnosticando que não souberam estimar o caráter essencial do valor, já sempre o interpretando como derivação. Especialmente na ética moderna, cujos influxos são sentidos na atualidade, a lei moral se mostra como tendo primado sobre a experiência do valor - interpretação que, como veremos, para nosso filósofo, apenas seria possível a uma ética desprovida da materialidade axiológica. Tal ética, antes mesmo de ser apontada em sua pretensa normatividade, deve ser designada como formalista.

Sendo ainda kantiana a matriz observada na reflexão ética contemporânea (sobretudo na Alemanha de Scheler, cuja filosofia acadêmica trazia profunda marca do neokantismo), não haveria lugar mais adequado para abordar tal formalismo senão na filosofia prática do próprio Immanuel Kant.

O formalismo na ética e a ética material dos valores começa, assim, com uma revisão da filosofia prática crítica e, contrariamente à expectativa que o título dessa obra de 1913 pode criar, o que Max Scheler oferece ali não é pro-

priamente uma ética fenomenológica dos valores, pois seu principal propósito 
é o de "[...] uma rigorosa fundamentação científico-positiva da ética filosófica, concernente a todas as questões essenciais e problemas fundamentais a esta advindos [...]" (Scheler 2000, p. 9).

Justamente por isso, a Ética de Scheler não deve ser tratada como uma objeção pura e simples a Kant (não devendo ser tratada como um filosofema antes que confiramos as posições schelerianas, como uma obra que faria acusações imerecidas resultantes de incompreensões e que, por isso mesmo, admiraria o fato de receber tanta acolhida) (Höffe 2005, p. 186). Na Ética, a crítica à ética kantiana tem papel apenas secundário, restringindo-se mesmo à parte inicial do trabalho e, não bastasse especialistas ligados mais de perto a Scheler lembrarem isso sempre que oportunamente (Henckmann, 1995), atentemos que o próprio autor já nos diz, em um de seus prefácios, e isso não sem deixar patenteado o alto conceito que tinha do filósofo de Königsberg:

A todo o momento o autor desejou submeter à crítica o que considerava falso nas posições de Kant mediante o descobrimento positivo do verdadeiro estado de coisas (Sachverhalts) de cada ponto. O autor não deseja atingir este verdadeiro estado de coisas por meio e em consequência de uma crítica à doutrina kantiana. Mesmo nessas seções críticas, o autor, em todo caso, parte do pressuposto de que a Ética de Kant - e a de nenhum outro filósofo mais recente — é até hoje a mais perfeita (Vollkommenste) apresentada, não na forma de visão de mundo (Weltanschauung) e de consciência de fé (Glaubensbewußtsein), mas antes na forma de uma distinção (Einsicht) cientificamente rigorosa para a ética filosófica. Além disso, a ética de Kant vem sendo, aqui e ali, criticada, corrigida e completada acertadamente pelos filósofos que o sucedem, mas sem que seus fundamentos mais profundos sejam abalados, assim pressupõe o autor. Nesses pressupostos vai inclusa a consideração incondicional pela realização de Kant, sendo autoevidente para o autor, mesmo ali onde as palavras de crítica não estão livres de farpas. (Scheler 1957, p. 9).

Com toda reverência que Scheler faz a Kant, a ética kantiana necessitaria passar por uma fundamentação, pois ainda arrolaria pressupostos que comprometeriam suas conclusões. A respeito da doutrina ética kantiana, Scheler dizia estar solidamente "[...] convencido de que este colosso de aço e bronze obstrui o caminho da filosofia à concreção de uma doutrina dos valores morais (Lehre von den sittlichen Werten)" (Scheler 1957, p. 30). Cabe então interrogar: Que suposições seriam essas a falsear a ética de Kant?

É no capítulo “A relação dos valores de 'bem' e 'mal' com os demais valores e com os bens" que Max Scheler começa propriamente sua análise da filosofia prática kantiana. No interior dele, Scheler identifica que a filoso- 
fia de Kant compartilha, com acerto, a distinção entre ética material e formal. O autor da Crítica da Razão Prática também sustenta o axioma que diz que qualquer elemento prático material seria da ordem do sensível, portanto, inadequado à requisição de necessidade absoluta própria à lei moral. Entendendo vedada a possibilidade de uma ética fundar-se na materialidade, Kant adota princípios exclusivamente formais para sua filosofia prática. Resulta disso uma moral baseada em princípios, em máximas e em mandamentos dos quais se deduziria a formulação de lei necessária, universal e objetiva (Paulsen, 1972).

Analogamente à Crítica da Razão Pura (teórica), lembremos que é também a lógica transcendental que atua na Segunda Crítica (prática), o que indicia que o "dever-ser" prescrito na lei moral já possui caráter a priori.

Kant, ao se ocupar, assim, do "bom" e do "mau" (fundamentais à ética moderna), entenderá, coerentemente às posições firmadas supra, que tais conceitos apenas se definiriam enquanto valores em conformidade com aquela lei. Desse modo, admite que o sentido e o valor do "bom" e do "mau" apenas se realiza em conformidade a um fim, e sempre em face de um "dever". Isso dá a saber da vocação legalista da filosofia prática de Kant, que tem nessa formalidade a fonte da obrigação moral e princípios estatuídos conforme o imperativo categórico de onde derivam valores como o de "bom" e o de "mau". (Paton, 1948). Para Scheler, tais valores, em vista do fim que é princípio fundamental da moralidade, ainda corresponderiam, respectivamente, às formas de "legalidade" e de "ilegalidade", o que significa dizer que o valor de "bom" seria afim ao que é legal e o de "mau", por sua vez, ao ilegal.

Ao examinar a ética kantiana no tocante às noções de valor, de bens e de fins, Scheler identifica premissas que lhe impedem de subscrever as posições do autor da Crítica da Razão Prática. Segundo ele, "[...] a primeira falta de Kant é negar que 'bem' e 'mal' sejam valores materiais" (Scheler 2000, p. 72) e, por não admitir a materialidade dos valores, avalia que Kant submete erroneamente valores aos bens, o que faz que, para esse pensamento, os valores sejam interpretados como derivados dos outros (Scheler 2000, p. 32), constituindo, assim, um primado de bens sobre valores. Mais do que tal primazia, ao sustentar que bens e valores morais apenas se definam referenciados a um fim, Kant incide num formalismo. Ora, mas em que consistiria esse formalismo? Resposta: O formalismo ético kantiano se consubstancia no fato de que seja a mera forma da nossa lei moral —- e não qualquer matéria — o que nos determina moralmente, conforme estatui a célebre fórmula do imperativo 
categórico. Scheler interpreta, contudo, que a propositura de uma ética formal pura seria a proposta de uma doutrina vazia de conteúdo axiológico. Para o fenomenólogo de Munique, essa posição kantiana derivaria de um "equívoco fundamental" (Scheler 2000, p. 32), sendo, pois, merecedora de enérgica rejeição. Isso por que:

É falha a tentativa feita por Kant de reduzir as significações das palavras-valor (Wertworte) "bom" e "mau" ao conteúdo de um dever [...] como também o dizer que não existia "bom" nem "mau" sem que houvesse este dever; tampouco se pode aceitar que estes valores se reduzam à mera "legalidade" ("Gesetzmäßigkeit") de um ato da vontade, à realização em conformidade com uma lei [...] (Scheler 2000, p. 32).

Para efetuar críticas como essas, Scheler conta, entretanto, com um elemento que não pertence à economia do pensamento de Kant. Trata-se da denominada experiência dos valores materiais valores que são descritos por Scheler como os que trazem a marca da materialidade. Em vista disso, também " [...] se depreende claramente que é possível encontrar um domínio material dos valores, e uma ordem nele, completamente independente do mundo dos bens e de suas formas cambiantes, e igualmente a priori frente a este" (Scheler 2000, p. 32). Essa experiência axiológico-material, inibida para Kant, é o que facultaria o que Scheler vislumbra como ética material dos valores. Fundamentalmente diversa de uma ética de bens e de fins, esta não concebe valores como resultantes de uma referência a um fim; para a fenomenologia axiológica scheleriana, são os valores materiais como os de "bom" e de "mau" que possuem verdadeiramente objetividade, autonomia e status apriorístico.

\section{Do apriorismo axiológico scheleriano}

Mas o que afinal teria vedado Kant da experiência de valores materiais a priori, a ponto de fazer com que adotasse a posição que valeria à acusação de formalismo? Autorizado por sua investigação, Scheler torna possível responder a esse questionamento com duas teses: a primeira advoga que Kant procede assim por ter um pensamento profundamente matizado por uma visão de mundo burguesa; a segunda defende que as coisas se dão desse modo pelo fato de o filósofo moderno não ter conhecido a fenomenologia, esta que, para Scheler, seria o único expediente que evidenciaria a materialidade apriorística dos valores. 
Antes de julgarmos frívola a primeira tese, saibamos que ela é bem circunstanciada e consolidada em obras posteriores, especialmente em Da reviravolta dos valores (escrita entre os anos 1912-1914, mas publicada em 1915). Abordado por interesse moral (menos que sociológico), Scheler não tem no burguês uma classe socioeconômica, pois, para ele, o burguês corresponde essencialmente a um tipo humano peculiar ou, mesmo, um ethos. Para o filósofo, trata-se de um tipo promovido por certa debilidade em vivenciar valores e orientar a própria vida segundo eles.

Na descrição de Scheler se identifica claramente a apropriação do repertório da filosofia de Nietzsche. Leitor da Genealogia da moral (1887), Scheler retirará a acusação nietzschiana feita ao judeu de que este seria "o grande odiador" (Nietzsche 1968, p. 25), transferindo para o burguês o peso de ser este propriamente o inconformado e, por isso mesmo, o fomentado pelo ressentimento. Compreendendo essa reatividade à vida e ao mundo como "[...] uma das fontes da reviravolta da ordenação eterna na consciência humana" (Scheler 2012, p.79), Scheler tem no burguês o epicentro da crise moral da época atual. Esse entendimento se deve justamente ao fato de o burguês sobrepor, aos valores, objetivos outros afetos às virtudes do mundo capitalista, como a prudência e a cordialidade interesseira no trato, o ascetismo na fruição dos bens e a obediência à positividade legal própria à lógica de contratos e de mercado, estes relacionados quase patologicamente à vontade de controlar a natureza e de assegurar-se dos riscos que a vida poderia oferecerlhe nas mais diversas circunstâncias.

Cabe aqui informar que Nietzsche não é o único presente na interpretação scheleriana da lógica burguesa. Também Werner Sombart (um sociólogo e economista alemão contemporâneo a Scheler) fornece intuições válidas nesse sentido. Entre os títulos assinados por Sombart têm relevo: A essência da indústria (1904) e Os judeus e a vida econômica (1911); todavia, é a obra $O$ burguês (1913) que parece ter prestado maior serviço a Scheler. Editada no mesmo ano da Ética e rapidamente assimilada nos anos subsequentes a esta, tal obra vem à guisa de contribuição à história moral e intelectual do homem econômico. Com esta, pretende Sombart (1920): “[... ] expor o espírito de nosso tempo em seu vir-a-ser e como ele hoje se afigura, procurando acenar à gênese do representante desse espírito: o burguês" (p. V). A análise crítica elaborada pelo sociólogo evidenciará os fatores espirituais na vida econômica (esta também como objeto da axiologia), a mentalidade do capitalista desde sua origem, a paixão pelo dinheiro e o afã por lucro, a o cálculo dos valo- 
res, o comportamento corporativo, as virtudes e as demais forças morais em ação no florescimento do capitalismo (filosofia e influências religiosas) e até mesmo um ensaio por tratar o que chamou de "natureza burguesa" (Bourgeoisnaturen). É em parte apoiado nessas análises que Scheler avalia que o ethos burguês (para o qual acima de tudo está o valor da utilidade) passa a se fazer sentir na filosofia ética moderna, a ponto de utilitarismos, pragmatismos, legalismos e, ainda, subjetivismos, racionalismos, idealismos, transcendentalismos e formalismos viessem grassar campo e significação, ainda que permanecessem alheios à experiência dos valores materiais (Dupuy, 1959).

A segunda tese de Scheler encontra elementos para sua expressão na Ética e em textos circunvizinhos, estando, portanto, mais diretamente relacionada ao seu projeto de axiologia fenomenológica e a sua compreensão de fenomenologia.

A fenomenologia é um modo de pensar que, partindo da consideração da consciência intencional, tem em conta o campo fenomenal intencionalmente aberto como o que permite um contato imediato com o mundo e com as coisas em seu âmbito. Nessa experiência, os objetos e o respectivo campo são dados e intuídos em suas vivências e na consciência: "[...] nada é 'intencionado' ('Gemeintem') que já não seja 'dado' ('Gegebenem'), conhecido nos é apenas o conteúdo da experiência fenomenológica. [Assim,] onde quer que o dado ultrapasse o intencionado, ou o intencionado não seja dado ele 'mesmo', ainda não há qualquer experiência fenomenológica pura (Scheler 2000, p. 70).

Deriva-se daqui que o fenômeno, tal como fenomenologicamente visado, não é tão somente uma aparência de algo real ou um aparecer, não podendo jamais ter sua determinação essencial conquistada por procedimentos empíricos de demonstração ou de dedução (estes ainda na chave de uma lógica de causa e efeito e observados no criticismo kantiano e no neocriticismo). De início, a fenomenologia oferece uma experiência viva do substrato do fenômeno. Em seguida, por meio do procedimento metodológico de redução fenomenológica, reconduz a inspeção do ver para a estrutura basal do fenômeno em face da qual este pode ser intuído em seus traços ideais e a evidência quanto a seu modo de ser pode ser auferida. Para Scheler, isso é o que Husserl chamava ““ intuição de essências', ou também -- como é possível chamá-la —- 'intuição fenomenológica' ou 'experiência fenomenológica"' (Scheler 2000, p. 70).

Ora, mas que elementos estariam na pauta da fenomenologia a ponto de esta voltar o seu interesse aos dados apriorísticos mostrados no fenômeno? Segundo nosso autor, o foco fenomenológico se ateria às qualidades intuídas 
em atos e todos os conteúdos objetivos, também aos atos mesmos e às conexões existentes entre eles e, ainda, às conexões essenciais que existem entre as essências dos atos e as essências das coisas (neste último seriam contemplados os valores dados cuja essência apenas é experimentada no sentimental) (Scheler 2000, p. 90).

Com o que podemos apresentar sumariamente nesse artigo, temos que Scheler termina por justificar sua tese indicando ser a fenomenologia "[...] uma atitude de um ver espiritual na qual podemos intuir (er-schauen) ou vivenciar (er-leben) algo que, de outro modo, permaneceria cerrado, a saber, um reino de fatos de determinada classe" (Scheler 1957, p. 380).

Com base nessa posição, vimos Scheler em condição para efetuar uma crítica a doutrina moral de Kant, justamente quando nesta estão em questão as noções de bem e de mal. Ressaltamos que a crítica de Scheler a Kant possui ampla envergadura e considerável complexidade; também que, ao tratar do tema e de seus contextos relacionados no seio da Ética.

Desse modo, declare-se que, embora com ênfase na noção de "experiência fenomenológica dos valores", o artigo que ora se encerra não trouxe senão uma abreviatura dos traços mais nucleares daquela exposição. Mesmo, no entanto, com os elementos módicos oferecidos aqui, poderíamos ensaiar uma interpretação aos moldes schelerianos da passagem que remata a Crítica $d a$ Razão Prática. Nesta, seu autor nos diz, de maneira magistral: "Duas coisas enchem o ânimo de admiração e veneração sempre novas e crescentes, quanto mais frequente e persistentemente refletimos sobre elas: o céu estrelado sobre mim e a lei moral em mim. Não preciso buscá-las ou presumi-las como se envoltas em obscuridade, ou em efusão além de meu horizonte; vejo-as" (Kant 1983, p. 300). Kant declara aqui sua certeza quanto à efetividade da lei moral. Fossem facultadas a ele as condições à experiência fenomenal de valores materiais irredutíveis, outra ordem apriorística se descobriria, fazendo que então tivesse, também a respeito dos valores em sua ética, a evidência plena que logra do firmamento sobre si.

\section{A tomada de valores e redução fenomenológica}

Se, como vimos, a fenomenologia deixa e faz ver um campo fenomenal e, no presente caso, o domínio específico dos fenômenos de valor, é preciso advertir que a vivência do fenômeno ainda não é, ela mesma, a evidência

indubitável pretendida pela fenomenologia. Ao se afirmar isso, passa a ser 
mesmo possível entrever aqui a diferença entre a fenomenologia e o fenomenismo. Para este (doutrina que conta com o fenômeno como traço constituinte do objeto do conhecimento empírico condicionado pelo aparato transcendental humano e a contraparte da "coisa-em-si" ou noumenon), o conhecimento se limita ao que o fenômeno manifesta (nesse sentido, mesmo Kant seria um fenomenista); para a outra a fenomenologia, o fenômeno é ponto de partida da investigação que se volta ao que nele mesmo é essencial. Para este retorno ao terreno das essências, reservou-se o nome: redução fenomenológica.

É por isso que "redução", aqui, não deve ser compreendida como diminuição ou abatimento de algo. Na "phenomenologische Reduktion", de Husserl, tal termo diz mais se interpretado a partir de sua origem latina, à luz da qual se identifica o verbo "reducere". Desse modo, reduzir significaria um novamente conduzir a... Mas... para onde reconduz a redução fenomenológica? A intuição tem seu foco nos objetos ideais e na idealidade dos mesmos objetos. Em seu A ideia de fenomenologia (1907), o filósofo aludirá à redução fenomenológica como, especificamente, a operação metódica que, não mais transigindo com pressupostos de realidade e empiricidade (próprios à atitude natural ingênua), exercita deliberada abstenção frente a qualquer pretenso conteúdo que não se faça em vista do fenomenal, reconduzindo-se assim ao terreno-base do fenomenal, para, então, nesses domínios, intuir com evidência a essência dos fenômenos (Zahavi, 2003). Por sua vez, essa "[...] essência fenomenológica é dada na experiência e esses modos de doação constituem a experiência do fenômeno como tal" (Hackett 2013, p. 15).

Max Scheler guardou atenção quanto a essa operação fenomenológica husserliana e, sobre ela, nos diz, de maneira pregnante:

Ser homem significa: lançar um enérgico "não" contra este tipo de efetividade. [... ] E Edmund Husserl não tinha em vista nada além disto ao articular o conhecimento da ideia de uma "redução fenomenológica", i.e., com um "corte" ou com uma "restrição" dos coeficientes casuais da existência das coisas do mundo, a fim de conquistar sua "essentia". Francamente não posso concordar em detalhes com a teoria de Husserl sobre essa redução, mas admito que nela se pensa o ato que propriamente define o espírito humano (Scheler 2008, p. 42).

Os motivos de Scheler declarar aqui (num escrito de 1928) sua discordância quanto aos termos da redução fenomenológica husserliana estão no fato de aquilo que chamamos, acima, de reconduzir-se ao terreno-base do fenomenal, a partir de 1913, significar para Husserl um retorno não à fenomena- 
lidade das coisas "elas mesmas" no ato de consciência que lhe é correlato, mas à consciência fenomenológica transcendental protagonista em seu Ideias. Não se pode negar, contudo, que o gesto redutivista husserliano é, em parte, apropriado por Scheler, afinal também este reconduz, à sua maneira, o foco de sua investigação a um campo fenomenal intencionalmente aberto no qual essências podem ser vivenciadas e captadas. Certo que a dimensão a priori que Scheler tem em vista aqui não é a de um ego cogito fenomenologicamente depurado pelo Husserl transcendentalista (menos ainda o terreno da razão prática para a qual o dever é princípio a priori em se tratando de ética). Scheler se volta ao valor material, elemento que considera o primeiro da dimensão moral.

Nesse caso há de se perguntar: Mas o que Scheler compreende estritamente por $a$ priori? A pergunta que questiona essa noção, até aqui apenas précompreendida, é o próprio filósofo quem a responde:

Designamos como "a priori" todas aquelas unidades significativas ideais e as sentenças que, prescindindo de todo tipo de posicionamento de sujeitos que as pensam e de sua real configuração natural, e prescindindo de posicionamento de um objeto sobre o que sejam aplicáveis, vêm por si mesmas no conteúdo de uma intuição imediata. Assim prescindindo de qualquer tipo de posicionamento (Scheler 2000, p. 103).

De maneira análoga a Husserl, para quem a lógica pura é terreno dos princípios lógicos e das significações ideais, Scheler divisa um terreno axiológico igualmente puro (portanto, do mesmo modo, independente de funções anímicas e psíquicas) no qual a experiência do valor pode ser tomada. Tal descoberta fenomenológica põe à luz um tipo peculiar de essências próprias a um mundo ontológico-axiológico. No referido mundo a priori de essênciasvalores não atua o entendimento, isso porque a experiência axiológica, por mais que seja objetiva, se oferece num registro intencional diverso daquele do conhecimento, não se sujeitando ao ato intelectivo, à determinação conceitual ou mesmo a uma definição teórica obediente à lógica de gênero próximo e diferença específica. Dito isso, acrescente-se que os conteúdos axiológicoapriorísticos também não se submetem a qualquer tipo de "delimitação", "demonstração" ou "dedução"; sendo assim, apenas a descrição fenomenológica, na medida em que deixa e faz ver o fenômeno, pode "mostrá-los". Scheler reforça isso ao afirmar que valores: 
[... ] não são meros termos conceituais que encontram sua realização em propriedades comuns às coisas que são portadoras desses valores. Isso já mostra o fato de que, se procurarmos tomar essas "propriedades comuns", no fundo nada nos fica nas mãos. Somente quando colocamos as coisas sob outro conceito que não seja o conceito de valor (Wertbegriff), quando perguntamos pelas propriedades comuns dos vasos ou das flores encantadoras, ou dos cavalos nobres, só então se oferece a possibilidade de assinalar essas propriedades comuns. Valores desse tipo não são, portanto, definíveis, apesar de sua indubitável “objetividade". Já os temos dados nas coisas, para só então designar as referidas coisas como "belas", "encantadoras" e "atraentes" (Scheler 2000, p. 36).

Ainda segundo o filósofo, insistir na tentativa de fixar características definindo ou conceituando o que seria o valor (e isso sem considerar sua ambiência axiológica própria) nos levaria não apenas a um erro teórico, mas a um equívoco moral com notadas sequelas. Isso indica, portanto, que valores devem ser coerentemente considerados em seu campo fenomenal específico, domínio objetual e de investigação inteiramente autônomo. Scheler chama atenção para o fato de haver "[...] um tipo de experiência cujos objetos são completamente inacessíveis à razão; para esses objetos a razão é tão cega como o ouvido seria para as cores [...]" (Scheler 2000, p.261). Ora, mas como então ter o fenômeno de valor diante de nós sem que o ver intelectivo da intuição tenha vez? Como chegar aos valores se estes são vedados ao ato intencional cognitivo? Se, para Scheler, não é possível conhecer valores, que "apreensão" seria então possível? Atentemos: dizer que não há um conhecimento possível dos valores não significa dizer que estejamos privados de uma experiência de valores, pois, para nosso filósofo, "Os valores nos são dados primeiramente ao sentir (Fühlen)".

Com essa indicação chegamos a capítulo crucial da obra de Scheler. Uma vez no terreno da fenomenologia dos valores, vemo-nos agora às portas de uma fenomenologia da vida sentimental. Os esforços para realizar tal projeto passam inicialmente pela apropriação dos expedientes da fenomenologia na viabilização de uma investigação dos valores, mas também pela confrontação produtiva da tradição filosófica, especialmente no turno moderno, em ao menos dois sentidos: 1) na indicação de como os sentimentos foram tratados e, em grande medida, negligenciados como fonte de experiência dos valores e 2) na revisitação da modernidade para recobrar, em posições filosóficas sui generis, como o sentimento permite a tomada, sem mediações, do a priori axiológico. 
Acerca do primeiro ponto - e a julgar pelo refinamento e pela sagacidade das análises de Scheler - o melhor começo para uma exposição seria promover ao leitor um encontro com a própria letra do filósofo:

A filosofia tende até o presente a um preconceito que tem sua origem histórica na maneira antiga de pensar. Este é uma separação completamente inadequada à estrutura do espírito em "razão" e "sensibilidade". Esta diferença demanda, por assim dizer, a atribuição de tudo que não é razão —- ordem, lei, etc. — à sensibilidade. Assim, toda nossa vida "sentimental" [...] passa a ser atribuída à "sensibilidade", também o amor e o ódio. [...] Em razão deste preconceito, fica sem ser colocado em questão se no plano do alógico de nossa vida espiritual pode ter, no conjunto de atos e funções, uma desigualdade de hierarquia com uma "originariedade" (Ursprunglichkeit) equiparável a dos atos mediante os que apreendemos os objetos ligados pela lógica pura - [...]. É natural que, com isso, também fiquem inquestionadas as ligações e oposições entre objetos e qualidades para os quais esses atos alógicos são dirigidos, e mesmo a correspondente legalidade (Gesetzmäßigkeit) a

priori este ato em si. [...] Decorre disso a seguinte consequência ética: que, ao longo de sua história, a ética se constituiu como absoluta e apriorística e, por isto, racional, ou bem como uma ética relativa, empírica (Scheler 2000, pp. 159-260).

É necessário refletir, e o empenho aqui é o de mostrar que, dada a divisão artificial entre razão e sentimento, toda vez que algo que não pertença à ordem da lógica (esta relacionada à intelecção) se apresenta, este é invariavelmente remetido ao domínio do sensível. Historicamente, desde cedo, o sensível esteve associado à obscuridade e à desordem interna; por isso mesmo, no seio da tradição, não recebeu a dignidade de ser pensado como domínio de objetos ideais ou de qualidades de valor autônomas (em verdade, até mesmo a pergunta sobre esta possibilidade teve sua falta sancionada). Para Scheler, não admitir essa possibilidade levou a ética moderna (em vista aqui o paradigma kantiano) a se estatuir como um modelo inteiramente desprovido de conteúdo axiológico e de estruturação formal ordenada pela lei moral.

\section{Ordre du cur}

Ao identificar fenomenologicamente a integridade de nossa vida espiritual, portanto não cindida como ora se pensou, Scheler torna possível suspender os influxos dos preconceitos tradicionais sobre o sentimento e indicar que este, embora completamente independente da lógica, é ato puro e tem, como correlato intencional, o conteúdo primigênio dos valores. Essa nossa interpretação encontra endosso em Frings, quando o especialista nos assevera que, para 
Scheler, "[...] há um primado na determinação dos conteúdos dos valores que é básico para os atos da consciência; as experiências sentimentais [...] são impregnadas por uma ordem de conteúdos de valores muito diferentes das leis da lógica pertinentes ao raciocínio e ao pensamento" (Frings 2001, p. 25). Após, ao reconduzir o foco da inspeção fenomenológica ao terreno em meio ao qual uma experiência das qualidades de valor se faz possível, temos o retorno ao campo intencional de base e ao âmbito no qual o fenômeno do valor pode ser, afinal, sentimentalmente tomado.

Chegamos então ao segundo ponto de nossa exposição: ao fazer inspeção sobre o panorama histórico da filosofia, nosso filósofo reconhece que apenas poucos pensadores (Agostinho e Blaise Pascal) fizeram oposição àqueles preconceitos e, ao fazê-lo, não chegaram a dar uma tematização suficiente ao ponto. Scheler divisa na ideia pascalina de "ordre du cur" (e em suas variantes: "logique du cur" e "raison du cur") ${ }^{3}$ um caminho para a reabilitação dos sentimentos como "órgãos" de tomada de valores. Para o fenomenólogo alemão, ao dizer que "Le cur a ses rasions", ${ }^{4}$ o filósofo francês "Compreende uma legalidade (Gesetzmäßigkeit) eterna e absoluta do sentir, amar e odiar, tão absoluta como a lógica pura, mas irredutível às leis do intelecto" (Scheler 2000, p. 260).

Mais do que fonte de inspiração, a metáfora pascalina do "coração" é verdadeiramente encampada por Scheler e é a partir dessa que dá corpo a sua fenomenologia da vida sentimental (Robledo, 1992). Com esta:

Distinguimos, de início, o "sentimento intencional de algo" de todos os meros estados sentimentais. Esta diferença, em si, contudo, com a significação que tem os sentimentos intencionais para os valores, i.e., até que ponto estes (sentimentos) são órgãos de tomada (de valores). De início: há um originário sentimento intencional (Scheler 2000, p. 261).

Levando assim adiante o insight de Pascal segundo o qual há uma genuína ordem do coração para a qual o entendimento não tem olhos de ver, Scheler indica que a tomada sentimental dos valores (o "coração") tem raio de atuação próprio. Isso quer dizer que, na "ordem do coração", os conteúdos do valor são tomados de modo tão inquestionável quanto os elementos da lógica ou das matemáticas, sem, entretanto, submeter-se à lógica do conhecimento, do entendimento, da razão.

\footnotetext{
${ }^{3}$ Respectivamente: "ordem do coração", "lógica do coração" e "razão do coração".
}

4 "O coração tem suas razões". 
É dispensável indicar que essas posições não são de todo pacíficas e, mesmo ali no seio do movimento fenomenológico, inclusive entre seus membros mais radicados, floresce a controvérsia. Roman Ingarden, para citar apenas um exemplo, é da opinião de que Scheler teria cometido uma forçosa generalização ao defender que quaisquer valores seriam apenas tomados sentimentalmente e que, portanto, não se deixariam determinar conceitualmente. Para esse, "Se fosse realmente este o caso, não seria então tampouco possível distinguir grupos ou, melhor dizendo, gêneros de valores; o que, em princípio, como mero fato, não se pode negar que se faz. Tampouco se poderiam comparar valores a respeito de seu gênero fundamental ou de sua altura" (Ingarden 2002 , p. 22). Uma tal afirmação nos leva a crer que Ingarden não prestou atenção em falas como esta de Scheler:

[...] qualidades de valor (Wertqualitäten), genuínas e verdadeiras, nos são dadas num campo próprio de objetos (Gegenständen), objetos que têm suas relações e conexões particulares, e que podem ser já como qualidades de valor (Wertqualitäten), p. ex., superiores e inferiores, etc. Mas se este é o caso, também há de haver entre elas uma ordem e uma hierarquia, cuja existência é independente de um mundo de bens (Gütenwelt) no qual estes se manifestam. (Scheler 2000, pp. 37-38).

Scheler indicia, aqui, que o caráter a priori dos valores não é apenas próprio a eles, mas também observável na ordem na qual eles já se oferecem. Desse modo, valores-fenômenos se permitem ser sentidos em sua organização intrínseca e em uma graduação hierárquica própria. Significa dizer que valores, desde que dados imediatamente no campo intencional de experiências que lhes é pertinente, também permitem que sintamos o lugar que já ocupam em certa ordenação. Assim, para Scheler, valores já são sentidos desde o modo como se dispõem em estratos superiores ou inferiores; permitindo, portanto, estimar como se ordenam, que altura ocupam e, ainda, a comparação frente a outros valores de graus diferentes na mesma ordem e hierarquia a priori.

Essa afirmativa suscita uma série de indagações: Mas como uma ordem axiológica seria a priori? No caso de acatarmos a ideia de uma ordem $a$ priori de valores, como esta teria se ordenado originalmente? Com base em que critérios ou juízos de bem tais valores se disporiam numa escala?

As respostas a essas perguntas podem ser dadas diante da observação atenta do que já foi dito. Daí ressalta-se que o caráter apriorístico dos valores se faz presente quando o compreendemos como esquema prévio para que de- 
terminado objeto se dê. Desse modo, não há quem estabeleça (criteriosa ou arbitrariamente) tal ordem de valores, pois eles mesmos se encontram ordenados de acordo com o sentido já dado na transcendência intencional própria a sua manifestação objetiva. Do mesmo modo, o critério para tal hierarquia axiológica é intrínseco a cada valor sem que dependa, portanto, de um juízo de bom ou de mau que os deliberariam como ocupantes dos graus mais altos ou mais baixos em tal escala (pensar em algo assim já seria tratar do estatuto dos valores como algo estabelecido a posteriori).

Poderíamos compreender, desse modo, que "Todos os valores [...] são qualidades materiais (materiale Qualitäten)" (Scheler 2000, p.39) e que também uma "[...] hierarquia de valores é [por sua vez] uma hierarquia material, uma ordem de qualidades valiosas" (Scheler 2000, p.45). Desse modo, valores e sua ordem expressam objetivamente uma realidade própria, uma na qual a identidade qualitativa dos valores se determina por sua valência e se ordena conforme a mesma realidade " $[\ldots]$ e, assim, independentes do movimento e das mudanças deste mundo de bens ao longo da história, para qual a experiência dos valores e sua hierarquia são em caráter 'a priori”' (Scheler 2000, pp. 37-38).

Embora isso signifique que tal ordem axiológica seja real e autônoma e que valores tenham posição imutável na mesma ordem. Scheler não nutre a pretensão de sustentar que a identidade objetiva dos valores se oferece a nós sempre evidentemente. Isso porque nossa estimativa desses valoes pode ser obnubilada por sentimentos, como, por exemplo, o ressentimento e a soberba, ou restringida por fatores históricos, sociais e culturais (Scheler, 2012).

Considerando o que acabou de ser dito, e retomando aqui os elementos históricos da filosofia que Scheler conjuga em sua análise, é possível ponderar que a filosofia da vida sentimental não apenas considera o âmbito intencional, mas que também tem em vista seus condicionamentos fáticos. Para Scheler, como se viu, são esses condicionamentos que introduzem a relatividade na tomada de valor e não seria errôneo asseverar que são mesmo esses, em outra escala, que obscurecem a realidade própria aos valores e que impedem uma tomada sentimental dos valores (Kelly, 2008) - fatores obnubilantes que afastam a possibilidade de uma investigação da vida sentimental e uma filosofia (fenomenológica) dos valores. 


\section{Conclusão}

O artigo que ora se conclui constituiu uma apresentação sumária de algumas das principais posições de Max Scheler em sua filosofia fenomenológica dos valores. Com esse, pudemos apresentar que Scheler se apropria da fenomenologia husserliana aplicando tal método aos valores, que, para esse, são igualmente fenômenos e, como tal, podem ser tomados em sua idealidade, em sua essência. Nosso filósofo compreende, então, que valores, em vez de representações ou estimativas psicológicas, têm uma materialidade própria que se mostra intencionalmente e possui determinidade a priori. Com base nisso, como vimos, Scheler pode criticar as éticas contemporâneas, pois em todas elas vigora o princípio kantiano do imperativo categórico, metacritério observado na filosofia moral de Kant e que se estabelece como um formalismo da razão. Max Scheler identifica nisso um formalismo que reduz os valores de bem e de mal, de bom e de mau, a uma conformidade abstrata a fins (e, portanto, sem materialidade). Ao propor valores essenciais depreendidos de fenômenos de valor, Scheler entende ter recobrado uma dimensão ontológica numa axiologia que a moral kantiana havia desprezado ou, ao menos, desconsiderado. Na sequência, ainda explorando o caráter apriorístico dos fenômenos e sua ordem intrínseca, abordamos como o filósofo de Munique compreende a tomada de valores. Para este, valores são captados sentimentalmente e a ordem a priori que lhes é própria pode ser divisada segundo o modo com que estes são sentidos. Após termos indicado, por fim, o quanto essa tese scheleriana é debitária de Agostinho e de Pascal. Pudemos concluir que a experiência fenomenológica dos valores, explorada por Scheler, dá novos rumos à axiologia e à ética contemporânea (ainda que, acerca desta segunda, nosso autor só tenha oferecido elementos para sua edificação).

\section{Bibliografía}

Derisi, O. N., 1979, Max Scheler: ética material de los valores, EMESA, Madrid.

Dupuy, M., 1959, La philosophie de Max Scheler: son évolution et son unité, vol. 1, PUF, Paris.

Frings, M. S., 2001, The mind of Max Scheler, Marquette University Press, Milwaukee.

Hackett, J. E., 2013, "Scheler, Heidegger, and the Hermeneutics of Value", en Journal of Applied Hermeneutics.

Henckmann, W., 1995, "Max Scheler: Fenomenologia dos valores", en Fleischer, M., Filósofos do século XX: uma introdução, Ed. Unisinos, São Leopoldo, pp. 125153. 
Höffe, O., 2005, Immanuel Kant, Trad. Valério Rohden e Christian Viktor Hamm, Martins Fontes, São Paulo.

Ingarden, R., 2002, Lo que no sabemos de los valores, Trad. Miguel García-Baró, Ediciones Encuentro, Madrid.

Kant, I., 1983, "Kritik der praktischen Vernunft", en Werke, Vol. 6, Schriften zur Ethik und Religionsphilosophie, Wissenschaftliche Buchgesellchaft, Darmstadt.

Kelly, E., 2011, Material ethics of value: Max Scheler and Nicolai Hartmann, Springer, Nueva York.

Nietzsche, F. W., 1968, "Zur Genealogie der Moral”, en Coli, G. y Montinari, M. (Eds.)., Nietzsche Werke: Kritische Gesamtausgabe, vol. Bd. VI, De Gruyter, Berlin-Nueva York.

Paton, H. J., 1948, The categorical imperative: A study in Kant's moral philosophy, The University Chicago Press, Chicago.

Paulsen, F. 1972, Immanuel Kant: His life and doctrine, Trad. J. E Creighton, A. Lefebvre, F. Ungar Publishing, Nueva York.

Ramos, D. R., 2017, “Amor e conhecimento na filosofia de Max Scheler”, Aoristo. International Journal of Phenomenology, Hermeneutics and Metaphysics, PR, v.2, n.1, Toledo, pp. 144-179.

Robledo, A. G., 1992, "Le cur”, en Estudios pascalianos, El Colegio Nacional, Fondo de Cultura Económica, México.

Souza. H. L., 1953, A axiologia e o personalismo de Max Scheler, Maceió, Ramalho.

Sánches-Migallón, S., 2010, "La ambivalente posición de Max Scheler ante la ética de Franz Brentano", Tópicos, n. 39, pp. 45-75.

Scheler, M., 2012, Da reviravolta dos valores, Trad. Marco Antônio Casanova, Vozes, Petrópolis.

, 2008, "Die Stellung des Menschen im Kosmos", en Frings, M. S. (Ed.), Später Schriften: Gesammelte Werke, Vol. 9., Bouvier, Bonn.

_ 2000, "Der Formalismus in der Ethik und die materiale Wertethik: Neuer Versuch der Grundlegung eines ethischen Personalismus", en Gesammelte Werke, Bd. 2. (Hrsg.) Frings, M. S. (Ed.), Bouvier, Bonn.

— 1957 , "Phänomenologie und Erkenntnistheorie", en Scriften aus dem Nachlass I: Zur Ethik und Erkenntnislehre, Bern.

Sombart, W., 1920, Der Bourgeois, Duncker \& Humblot, Munique e Leipzig.

Zahavi, D., 2003, Husserl's Phenomenology, Stanford University Press, Stanford. 